\title{
MRヘッドに対応した垂直磁気記録媒体 Perpendicular Magnetic Recording Medium Optimized for an MR Head
}

\author{
池田圭宏、園部義明、内田 博、豊岡孝資 \\ 日本 I B M東京基礎研究所 \\ Y. Ikeda, Y. Sonobe, H. Uchida, and T. Toyooka \\ IBM Research, Tokyo Research Laboratory, IBM Japan
}

\begin{abstract}
We optimized a perpendicular magnetic recording medium for use with a merged MR head designed for longitudinal media. The dual-layer perpendicular medium with a low-Hc underlayer, has problems in write operation and MR bias current dependence of signal distortion. The singlelayer $\mathrm{Co}-\mathrm{Cr}$ perpendicular medium has similar MR bias current dependence of the signal amplitude and the signal distortion to the longitudinal medium. The $\mathrm{Cr}$ content increase from conventional $22 \%$ to $28 \%$ results the signal to noise ratio increase. The $\mathrm{Ti}$ underlayer contributes to increase the recording resolution but not to decrease the medium noise. The $\mathrm{Cr}$-rich $\mathrm{Co}-\mathrm{Cr}$ perpendicular medium with large thickness and low Ms value is expected to be used with the future high-sensitivity MR head for realizing high-density recording of more than 10 Gbits/inch ${ }^{2}$.
\end{abstract}

\section{1.はじめに}

ハードディスクの面密度は年率 $60 \%$ 割合 で増加している。これには、MRヘッドの技術 が大きく貢献している。近い将来、大容量八一 ドディスクで使われるヘッドの大半が MR ヘ ッドとなり、その感度もスピンバルブなどの採 用により大幅に向上すると予想される。

一方、垂直磁気記録方式は、インダクティブへ ッドと組み合わせて $600 \mathrm{kFCI}$ 以上の線記録密 度の可能性が示されている[1]。垂直磁気記録方 式のハードディスクを実用化する上で、面内記 録用の MRヘッドをそのまま使えれば、容易に 開発が進められると考えられる。
我々は、現在の面内記録用 $\mathrm{MR}$ ヘッドに適し た垂直媒体の検討を進めている。本報告では、 これまでに我々が検討してきた二層膜、単層膜、 Cr-rich 単層膜 [2-4] などの垂直媒体と面内記 録用 MR ヘッドとを組み合わせた系の特性を 比較検討した結果について報告する。また垂直 媒体が面内媒体に対して、どのようなメリット があるかについても論じる。

\section{2. 実験方法}

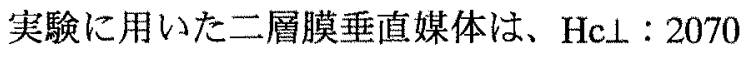
Oe、Ms : $370 \mathrm{emu} / \mathrm{cc}$ 、膜厚 : $90 \mathrm{~nm}$ の記録層を 持つ $\mathrm{CoCrTa} / \mathrm{FeNi}$ 媒体である。単層膜媒体は $\mathrm{C} 0-\mathrm{Cr}$ 膜を対向ターゲット式スパッ夕装置によ って、2.5インチ・ガラスディスク基板上に直 接または、結晶配向度制御のための $\mathrm{Ti}$ 下地層 を形成した上に作製した。成膜時の基板温度は $200^{\circ} \mathrm{C}$ である。合金ターゲットの組成比を変光 て、Cr 量が 15-30at.\%の媒体を作製した。ディ スクの円周方向の均一性を得るため、基板を 30 $\mathrm{rpm}$ で自転させながら成膜を行った。カーボン 保護膜 $22 \mathrm{~nm}$ を形成し、潤滑剤を $1 \mathrm{~nm}$ 塗布し た後、記録再生特性を測定した。比較のために 用いた面内媒体の $\mathrm{Hc} / /$ は $1900 \mathrm{Oe} 、 \mathrm{Mrt}$ は 0.9 $\mathrm{memu} / \mathrm{cm}^{2}$ である。測定に用いたへッドは、Read トラック幅 $2.5 \mu \mathrm{m}$ 、シールドギャップ長 $0.3 \mu \mathrm{m}$ 、 Write トラック幅 $3 \mu \mathrm{m}$ 、Write ギャップ長 $0.6 \mu \mathrm{m}$ のマージ型 MR ヘッドである。測定は線速度 $8.29 \mathrm{~m} / \mathrm{s} 、$ ヘッド浮上量約 $40 \mathrm{~nm}$ で行った。 $\mathrm{S} / \mathrm{N}$ 比は、その記録密度時の信号の大きさ $(\mathrm{Vp}-\mathrm{p})$ を $40 \mathrm{MHz}$ のバンド幅で積分したノイズ(Vrms)で 割って求めた。ノイズ評価には、その積分值を 


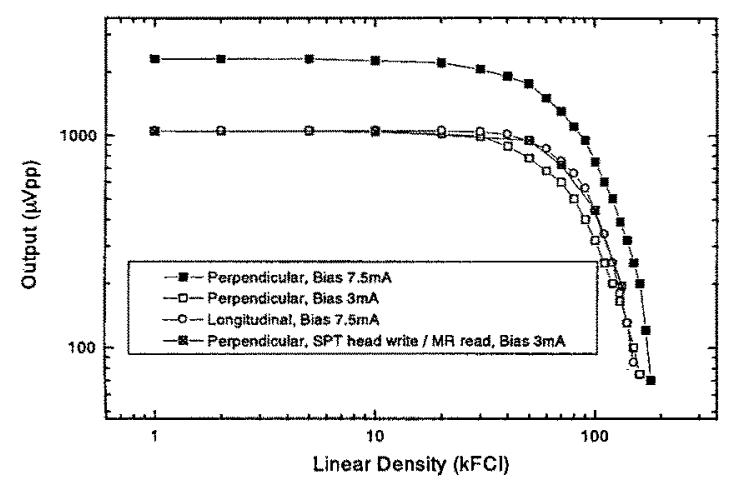

Fig. 1 二層膜媒体の記録密度特性

Isolate Pulse の大きさ(Vo-p)で規格化した值を 用いた。膜の粒子間の磁気的相互作用 $\Delta \mathrm{M}$ を VSM を用いて測定した。X 線回折装置、およ び TEM を用いて膜の結晶配向度および平均粒 径を測定した。

\section{3. 実験結果および考察}

\section{$3-1$. 二層膜}

$\mathrm{MR}$ バイアス電流 $3 \mathrm{~mA}$ と $7.5 \mathrm{~mA}$ を用いて、 垂直二層膜媒体の線記録密度特性を評価した。 この結果をバイアス電流 $7.5 \mathrm{~mA}$ の面内媒体の 特性と合わせて Fig. 1 亿示す。垂直媒体の低線 密度域での出力は、 $7.5 \mathrm{~mA}$ で面内媒体の 2 倍以 上、 $3 \mathrm{~mA}$ で同程度の值となった。 $\mathrm{D}_{50}$ は面内媒 体の $98 \mathrm{kFCI}$ に対して $80 \mathrm{kFCI}$ と低かった。線 記録密度が低い原因を検討するために、主磁極 厚 $0.5 \mu \mathrm{m}$ の単磁極型薄膜ヘッドを用いて書き 込みを行い、MR ヘッドで読夕出しを行って評価 した。この結果、高密度において出力改善が見 られ、98 kFCI の $\mathrm{D}_{50}$ が得られた。記録ポール 長が $4.25 \mu \mathrm{m}$ から $0.5 \mu \mathrm{m}$ と小さくなったこと、 および書き込み時の面内磁界成分の減少など が原因と考えられる。線記録密度の向上にはマ 一型 MR ヘッドの記録部の改良が必要であ る。一方、Overwrite 特性注内媒体の約半分の 記録電流で-50 dB の高い值が得られた。この Overwrite 特性と高い出力が、二層膜を用いたと きのメリットである。

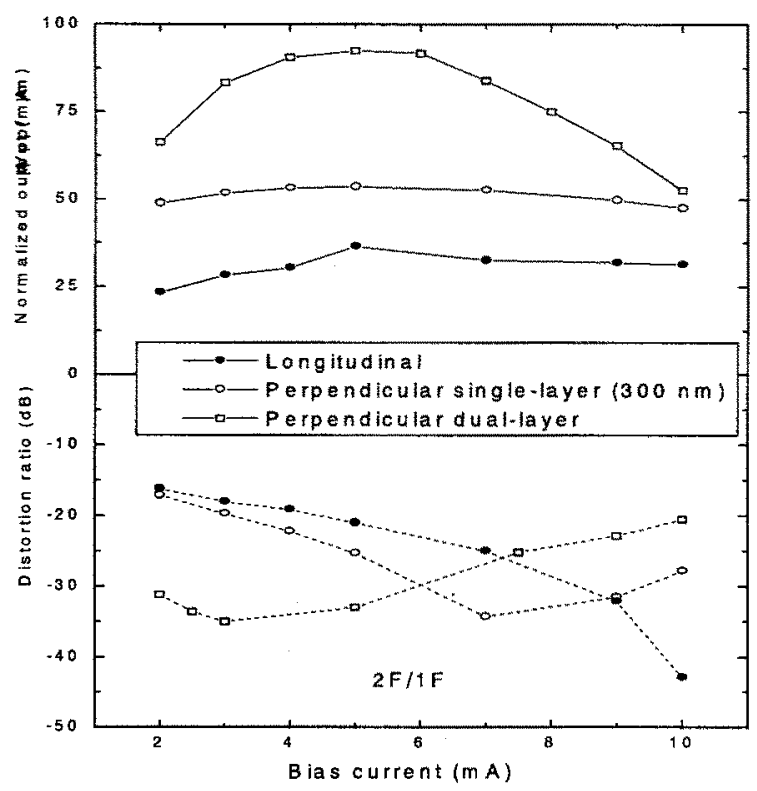

Fig. 2 各媒体の MRバイアス電流に対する規格 化出力の依存性

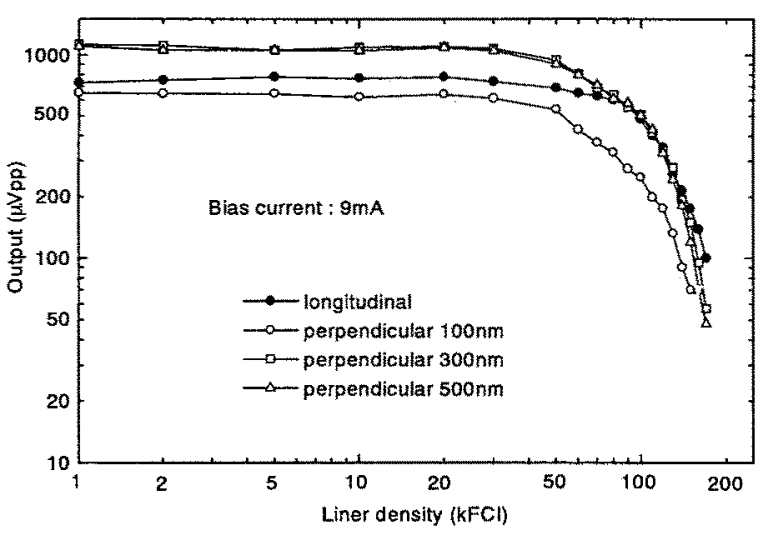

Fig.3 単層膜媒体の記録密度特性

\section{$3-2$. 単層膜}

Fig. 2 に単層膜媒体の MRバイアス電流に対 する規格化出力と歪み率の依存性を示す。膜の

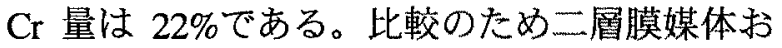
よび面内膜媒体の值も同時に示した。膜厚 300 $\mathrm{nm}$ の単層膜では、出力が面内膜の約 1.5 倍得ら れた。また、規格化出力のバイアス電流依存性 は小さく面内膜の特性とよく似ている。二層膜 のときバイアス電流依存性が大きいのは、磁束 量が大きいため、MR素子が飽和したことなど が考えられる。歪み率も電流の増加とともに滅 少し、 $9 \mathrm{~mA}$ で面内膜とほぼ同一の值が得られ 


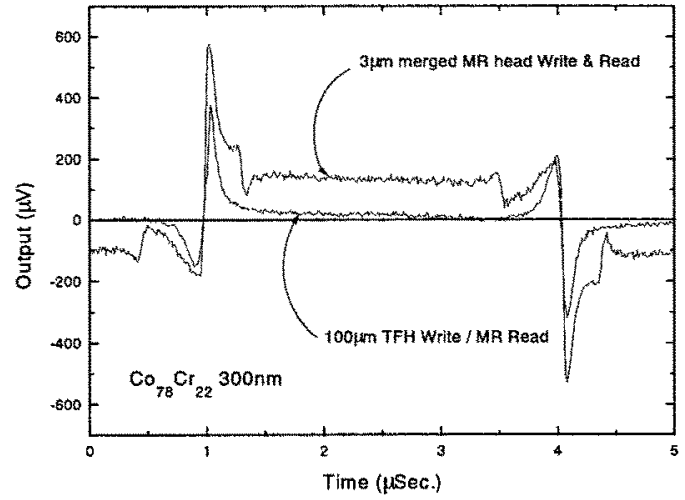

Fig. 4 記録ヘッドのトラック幅の違いによる MR 再生波形の変化

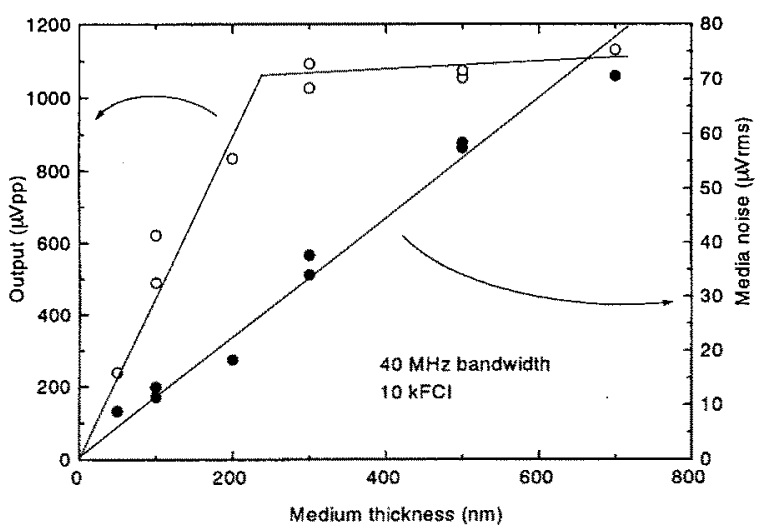

Fig. 5 出力およびノイズの膜厚依存性

た。これらの結果から、面内記録用に設計され た MR ヘッドをそのまま単層膜に用いても良 好な特性が期待できる。以後の単層膜の評価で は、バイアス電流を $9.0 \mathrm{~mA}$ とした。

面内膜と膜厚 $100,300,500 \mathrm{~nm}$ の垂直膜の線 記録密度特性を測定した結果を Fig.3に示す。 $\mathrm{D}_{50}$ はそれぞれ $115,80,100,98 \mathrm{kFCI}$ である。単 層垂直膜では、面内膜の 2 倍から 10 倍の膜厚 でも、かなり高密度まで記録再生ができる。た だし、膜厚 $100 \mathrm{~nm}$ では、ガラス基板上に直接 形成した際にできる約 $30 \mathrm{~nm}$ 程度の初期成長層 の影響が無視できなくなり、VSM およびトルク 分析において、面内異方性が若干見られ、Hk が約 $2.5 \mathrm{kOe}$ に滅少している。このため、記録 再生特性が悪くなっている。

Fig. 4 に膜厚 $300 \mathrm{~nm}$ の媒体とマージ型 MRへ ッドを用いた場合の再生波形を示す。100 $\mu \mathrm{m}$

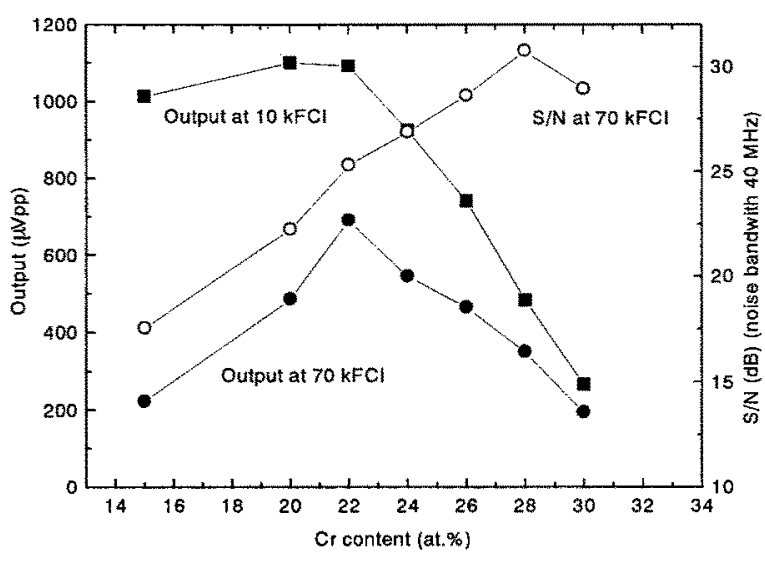

Fig. 6 出力およびノイズの $\mathrm{Cr}$ 量依存性

のトラック幅を持つ thin-film head で記録を行 い、MR ヘッドで再生を行った場合の波形を 併せて示した。Write トラック幅が $3 \mu \mathrm{m}$ のとき

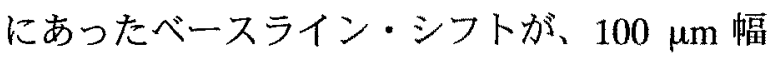
で書き込みを行ったときはほとんど見られな い。これより、ベースライン・シフトは、トラ ック兩サイドから回り込む磁束によって生じ ていると考えられる。

Fig. 5 に $10 \mathrm{kFCI}$ 記録時の出力およびノイ ズの膜厚依存性を示す。ノイズは膜厚の増加と ともに単調に増加しているが、出力は $300 \mathrm{~nm}$ 付近で飽和している。これは、現在実用化され ている高密度の面内記録媒体の膜厚 $30 \sim 50 \mathrm{~nm}$ と比べて約 10 倍の膜厚である。この出力飽和 の原因は、書き込み時の不飽和によるものと、 読み出し時における膜下面の磁荷の影響の緩 和によるものが考光られる。

\section{3-3． Cr 量増加による効果}

前項で示したように、単層膜媒体では膜厚が 大きくても高密度記録が可能である。また、膜 厚を大きくすることにより、減磁界を低減し、 記録磁化を安定化させる効果も期待される。面 内媒体で線記録密度を上げるためには、逆に膜 を薄くして減磁界を低減する必要がある。膜厚 が $20 \mathrm{~nm}$ まで下がってくると、作製の歩留まり や膜厚均一性の問題が生じる。膜厚が大きくて も高い記録密度が得られることは大きなメリ ットである。 


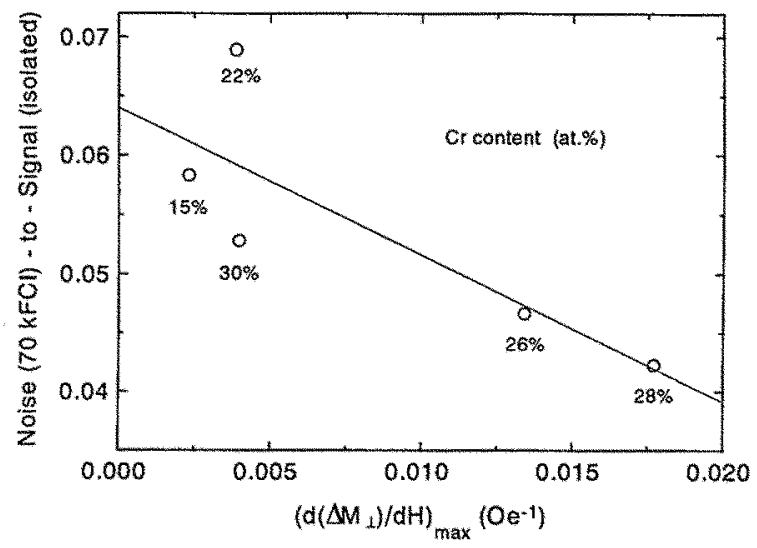

Fig. $7 \Delta \mathrm{M}$ 曲線の最大傾斜量と媒体ノイズの関 係

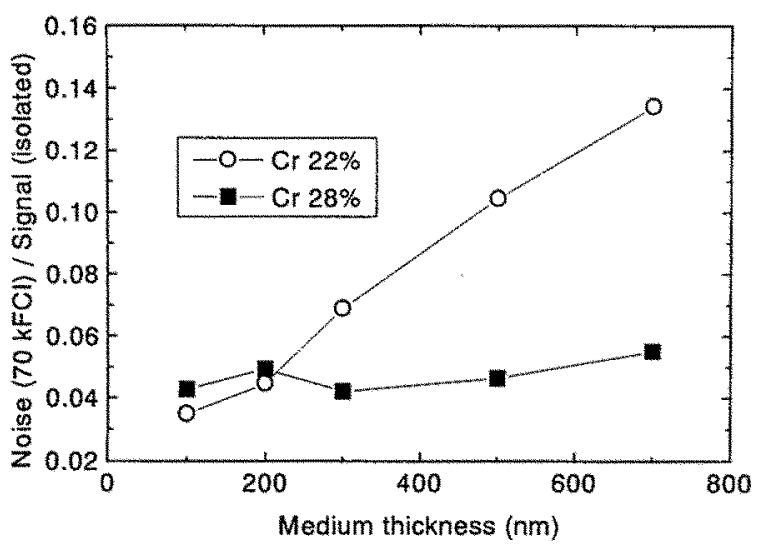

Fig. 8 媒体ノイズの膜厚依存性

膜厚の大きな垂值媒体を実用化する上での 一つの課題は、媒体ノイズの低減である。我々 はノイズ低減を目的として、膜厚 $300 \mathrm{~nm}$ の比 較的厚い $\mathrm{Co}-\mathrm{Cr}$ 媒体の $\mathrm{Cr}$ 量を增加させてその 記録再生特性を測定した。10 kFCI、70 kFCI 記 録時の再生出力および $70 \mathrm{kFCI}$ 記録時の $\mathrm{S} / \mathrm{N}$ 比 の $\mathrm{Cr}$ 量依存性を Fig. 6 に示す。再生出力は 22 at.\%で最大值を示し、Cr 量をさらに增加させる と出力は低下した。ところが、S/N 比は22 at.\% からCr量を増加させるとさらに问上し、28 at.\% で最大值 $31 \mathrm{~dB}$ が得られた。 MRヘッドなどの 高感度ヘッドを用いるときには、従来より 6 at.\%程度 $\mathrm{Cr}$ 量を増加させた媒体を用いる方が、 $\mathrm{S} / \mathrm{N}$ を改善できる。

面内媒体で用いられたノイズの分析手法の 一つとして、粒子間の磁気的相互作用 $\Delta M$ の評 価がある。 $\Delta \mathrm{M}$ の有効印加磁界に対する傾き
$(\mathrm{d}(\Delta \mathrm{M}) / \mathrm{dH})$ の最大值と媒体ノイズには相関が ある。傾きの最大值が大きい場合には、粒子間 の磁気的相互作用が大きく、ノイズが大きくな る[5]。ところが、垂直媒体の場合には、Fig. 7 に示すように、70 kFCI 記録時のノイズは $(\mathrm{d}(\Delta \mathrm{M}) / \mathrm{dH})$ の最大值が大きくなると小さくな る。これは $\Delta \mathrm{M}$ が大きい Cr-rich 媒体では、粒子 の膜面内の孤立化により、膜面に垂直方向の相 互作用が相対的に大きくなり、一つのコラム内 の磁化が同一方向にそろえられ、コラム一つが 単粒子のようにふるまうためと考えられるが 更なる考察が必要である。

膜厚およびそれに伴う粒径の変化がノイズ に与える影響について調べた。70 kFCI 記録時 のノイズを孤立再生波高で規格化した值、N/S 比の膜厚依存性を、Cr 22 at.\%㧍よび 28 at.\%の 媒体について測定した。この結果を Fig. 8 に示 す。 $300 \mathrm{~nm}$ より膜厚を薄くすると、N/S 比は、 22 at.\%より 28 at.\%の方が低い。膜厚の薄い領 域では Isolate Pulse の大きさも同時に小さくな るので、規格化ノイズに顕著な差は見られない。 $300 \mathrm{~nm}$ より厚い 22 at.\%の媒体では膜厚に比例 して N/S 比が増大している。これに対して 28 at.\%では、膜厚による変化は極妙ない。こ のことは、先に述べた、膜厚方向の単粒子化に よって、膜厚が増加しても粒子数が増加しない ことで説明づけられる。

TEM による観察からそれぞれの平均粒径を 測定したところ、22 at.\%および 28 at.\%とも膜 厚に比例して粒径が大きくなっており、大きな 差異注られなかった。Cr-richの媒体のノイズ 発生メカ二ズムが、從来の媒体とは異なってい ることを示唆している。

\section{3-4. Ti下地層による効果}

垂直媒体の結晶配向性を向上させることに より、高い線記録密度を得られることが報告さ れている[6]。単層膜媒体に配向制御層として 25 $\mathrm{nm}$ の $\mathrm{Ti}$ 下地層を用いたときの $\mathrm{D}_{50}$ の媒体膜厚 依存性を Fig. 9 に示す。図には、Cr 22\%および Cr 28\%の膜を Ti 下地層上に形成した場合と、 ガラス基板上に直接形成した場合について示 


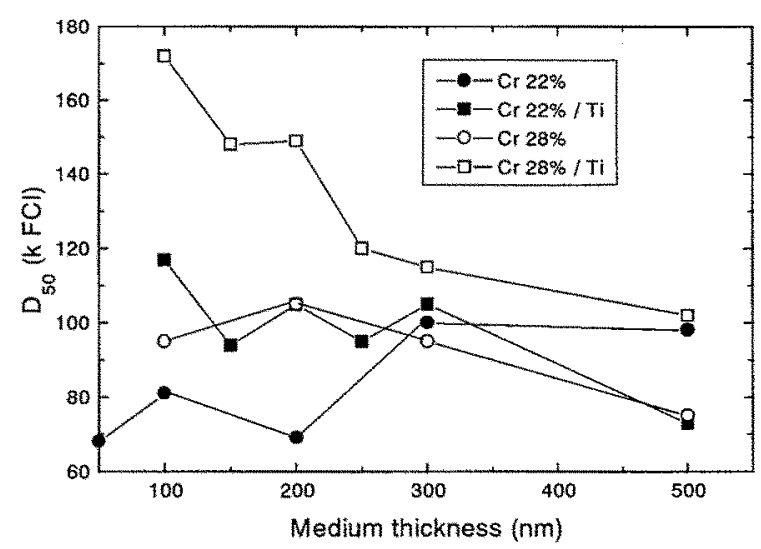

Fig. $9 \mathrm{Ti}$ 下地層の有無による $\mathrm{D}_{50}$ の膜厚依存性 の違い

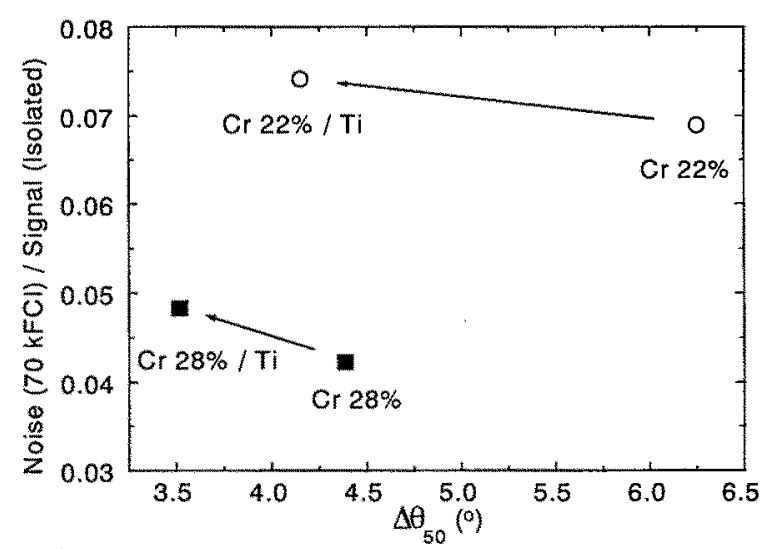

Fig. 10 結晶配向度と媒体ノイズの関係

した。Ti下地層を用いた場合には、特に $200 \mathrm{~nm}$ 以下の媒体膜厚において $\mathrm{D}_{50}$ 荗向上している。 この効果は、Cr 28\%の媒体の方がより大きい。 この効果は主に、低密度記録領域での絶対的出 力が Cr 28\%の薄い媒体で低下しているためで あり、高密度領域での絶対的出力に膜厚による 大きな違いは見られなかった。Ti下地層は、200 $\mathrm{nm}$ 以下の薄い媒体で分解能を向上させる效果 がある。200 nm以上の膜厚では、ほとんど効 果がみられない。

結晶配向度とノイズとの関係を調べるため、 $\mathrm{Ti}$ 下地層を用いた膜と下地層の無い膜のノイ ズを Cr 22 at.\%および28 at.\%について測定した。 Fig. 10 にそれぞれの膜の結晶配向度 $\Delta \theta_{50}$ と $70 \mathrm{k}$ FCI 記録時のノイズとの関係を示す。22 at.\%お よび 28 at.\%の膜の両者とも、 $\mathrm{Ti}$ 下地層を用い ることにより、結晶配向度は向上しているが、 ノイズは若干増加している。すなわち、結晶配
向度を向上することが必ずしも $\mathrm{S} / \mathrm{N}$ 向上につ ながらない。Cr 22 at.\%および 28 at.\%の膜を用 いて前述の $\Delta \mathrm{M}$ 測定を行ったところ、Ti 下地層 の有無に関わらず、ほぼ同じ $(\mathrm{d}(\Delta \mathrm{M}) / \mathrm{dH})_{\max }$ の值 が得られた。このことから、媒体の $\mathrm{S} / \mathrm{N}$ 比は結 晶配向度よりも、磁性層の磁気的相互作用に依 存しているということができる。

\section{4. まとめ}

以上、面内記録用 MRヘッドを様々な重直媒 体と組み合わせたときの特性について述べた。 二層膜媒体は出力が大きいが、実用化のために はヘッドの大幅な変更が必要となる。単層膜は、 面内膜に近い特性を示し、比較的厚い膜厚でも 高線密度記録が可能である。Cr 量を従来の $22 \%$ から 28\%程度まで増加させることにより、膜厚 の大きな媒体でもノイズを下げることができ た。Ti 下地層は線記録密度向上には役立つが、 ノイズ低下にはあまり効果がない。

面内磁気記録媒体では記録密度向上とノイ ズ低隇のために、膜厚を $15 \mathrm{~nm}$ 程度まで下げる 必要がある。このように薄い媒体をディスク全 面に均一に形成し、かつ欠宿密度を下げるのは 極めて困難になる。また、1ビットの体積が減 少し、熱的擾乱によるデー夕消失の問題が発生 するおそれがある。

垂直記録媒体が、これらの問題を解決する手 段の一つになるためには、膜厚の大きい単層垂 直媒体についてさらに検討を進める必要があ る。 $\mathrm{Cr}$-rich $\mathrm{Co}-\mathrm{Cr}$ 垂直媒体㥗、面内媒体を置き 換える有望な候補の一つであると言える。

\section{5 ，参考文献}

[1] S. Yamamoto, Y. Nakamura, and S. Iwasaki, IEEE Trans. Magn. Vol.23-5, 2070(1987)

[2] Y. Sonobe, Y. Ikeda, H. Uchida, and T. Toyooka, IEEE Trans. Magn., Vol. 31, No. 6, 2681(1995)

[3] 池田圭宏、園部義明、内田 博、豊岡孝資、 日本応用磁気学会誌 Vol. 19, suppl. No. S2, 126 (1995)

[4] Y. Ikeda, Y. Sonobe, H. Uchida, and T. 
Toyooka, IEEE Trans. Magn., to be published. (INTERMAG96 CQ-3)

[5] K. O'Grady, R.W. Chantrell, and I. L. Sanders, IEEE Trans. Magn., Vol. 29, No. 1 (1993) 286.

[6] M. Futamoto et al., IEEE Trans. Magn., Vol. 21 1426 (1985) 